\title{
Effect and evaluation of prying action for top- and seat-angle connections
}

\author{
Ali Ahmed ${ }^{1} \cdot$ Rafiq Hasan ${ }^{2}$
}

Received: 29 March 2014/ Accepted: 8 April 2015/Published online: 18 April 2015

(c) The Author(s) 2015. This article is published with open access at Springerlink.com

\begin{abstract}
Nonlinear finite element (FE) static analyses of top- and seat-angle connections were performed using ABAQUS standard to investigate the influence of connection parameters and its properties on prying action developed due to the interaction between column flange and top angle's vertical leg. Contact phenomenon between two interfaces with finite sliding and bolt pretension in the initial step of analysis was considered in the FE model. FE analysis results were compared with the experimental ones to examine the applicability of the FE model. Then, the location of plastic hinges in connection assemblages was investigated at the ultimate state of the connection and a parametric study was performed varying connection parameters, material properties of connection assemblages, and magnitude of bolt pretension to visualize their effects on prying force and on the position of prying force on top angle's vertical leg. Current study shows that plastic hinges not only develop at top angle's heel and bolt hole region but also in the bolt shank that differs from some assumptions of power model (Kishi and Chen 1990): (1) top angle thickness and gage distance from angle heel to bolt hole center line have an distinct effect on prying action; and (2) distributed prying force developed near the region of the top edge of tension angle's leg adjacent to column flange can contribute to the failure of the connection. Finally, a mathematical formulation to identify the location of prying force action point is proposed.
\end{abstract}

Ali Ahmed

aliahmed@stamforduniversity.edu.bd

1 Department of Civil Engineering, Stamford University Bangladesh, Dhaka, Bangladesh

2 408-70 Absolute Avenue, Mississauga, ON, Canada
Keywords Top- and seat-angle connection - Finite element analysis - Prying action - Location of prying force

\section{Introduction}

Nowadays semi-rigid connections are of considerable interest to researchers and design offices because they are easy to install in steel frames and have considerable energy dissipating capacity under seismic excitation. Recognizing the importance of these connections in practice, AISC (2001, 2005) specifications recommend inclusion of this group of connections in the Partially Restrained (PR) construction category. However, detail design guidelines for this group of connections, especially for angle type of connections, are not developed yet.

In the AISC-ASD specifications, top- and seat-angle connections are treated as connections intended only for transferring beam shear force. However, experimental evidence and the present study on the connections show that besides transferring beam shear force, this type of connection transfers fairly considerable beam end moment to the column. When transferring this moment through the top angle to the column, an increase in tensile force is incurred in the bolts due to local deformation of the top angle's vertical leg. This additional tensile force is commonly known as the prying force ( $Q$ in Fig. 4). Recently, researchers have paid serious attention to this additional force in their mathematical representation of connection behavior. Initially, the T-stub modeling concept has been used for designing extended end plate connections and modified for use to design angle type of connections (Faella et al. 1996; CEN 1997). However, the T-stub model is not accurate enough to represent actual deformation pattern of true angle type of connections at failure, and may not correctly estimate the connection strength. 
Accordingly, in the 80s and 90s, available moment-rotation models were modified and improved by incorporating more realistic representation of prying action (Kishi and Chen 1986, 1990; Faella et al. 1996; CEN 1997). Kishi and Chen's (1990) connection model (named as power model) considered bending and shear deformations of the angle, but disregarded deformation of bolts for deriving the ultimate moment capacity of angle type of connections. To establish a rational prediction model for precise representation of the $M-\theta_{r}$ curves of the connections, the effect of prying action on connection behavior should not be ignored. In this context, FE analyses were performed to investigate the contribution of prying action in momentrotation behavior (Ahmed 2002; Komuro et al. 2006). The places of plastic zones, effect of connection parameters on prying action and the magnitude and location of prying action are also examined for tracing a failure mechanism of the connection. Finally, based on the FE analysis and experimental results (Azizinamini et al. 1985; Harper 1990), an equation determining the location of prying force at the final load level is suggested for general application of estimating the ultimate moment capacity of the connection.

\section{FE analysis of connections}

A 3D FE mesh of the steel top- and seat-angle connection is constructed employing ABAQUS/CAE (2005) structural analysis modeling tool to execute a nonlinear static analysis. A complete list of connections with geometric details which are used for FE analysis to study the connection parameter and property effects on prying action is provided in Table 1 . This list includes connections used by the first author in his previous study (Ahmed et al. 2001) and an additional connection designated as "Test 3" which was tested by Harper in the University of South Carolina (Harper 1990).

\section{Mesh generation of FE model}

In the FE analysis modeling, top and seat angles, bolts, beam and stub column of the tested connection are idealized by homogeneous steel material and modeled with eight-node solid (brick) elements, which are identified as C3D8R elements in ABAQUS. These elements with reduced integration are generated considering precise constitutive law of integration and are very suitable for nonlinear static analysis allowing finite strain and rotation in large-displacement analysis (ABAQUS 2005). Moderately fine mesh is used to construct the mesh of the connection model to obtain close representations to the experimental specimens. The mesh of the connection model strictly followed the geometries of the tested connection. The measurements of all connections including Test 3 are shown in Table 1 . The connection parameters shown with symbols in Fig. 1 are enlisted in Table 1. The other connection parameters shown with numeric values in the same figure are kept unchanged in all connection models. Because of symmetry, one quarter of the connection is used for mesh generation of all FE model connections with half of span length (such as, $1.829 \mathrm{~m}$ for Test 3 is illustrated in Fig. 2). Bolts in the mesh are divided into shank, head and nut elements to consider their individual affections on connection behavior. The bolt hole diameter is supplied $1.6 \mathrm{~mm}(1 / 16 \mathrm{in}$.) larger than the diameter of the bolt in accordance with Azizinamini et al. (1985) and Harper's (1990) test data. The total number of elements and nodes defined in the FE mesh of model Test 3 are 8652 and 16,421 , respectively. As an example, the mesh patterns

Table 1 Geometrical Properties of top- and seat-angle connections

\begin{tabular}{|c|c|c|c|c|c|c|c|c|}
\hline \multirow[t]{2}{*}{ FE model } & \multirow[t]{2}{*}{ Column section } & \multirow[t]{2}{*}{ Beam section } & \multicolumn{5}{|c|}{ Top and seat angles } & \multirow{2}{*}{$\begin{array}{l}\text { Bolt diameter } \\
d_{\mathrm{b}}(\mathrm{mm})\end{array}$} \\
\hline & & & Angle section & $l(\mathrm{~mm})$ & $g_{t}^{\prime}(\mathrm{mm})$ & $r(\mathrm{~mm})$ & $q(\mathrm{~mm})$ & \\
\hline $\mathrm{A} 1, \mathrm{~A} 1 \mathrm{~m}, \mathrm{~A} 1_{\mathrm{Po}}, \mathrm{FE} 5, \mathrm{FE} 6$ & $\mathrm{~W} 12 \times 96$ & $\mathrm{~W} 14 \times 38$ & $\mathrm{~L} 6 \times 4 \times 3 / 8$ & 203.2 & 63.5 & 139.7 & 88.9 & 22.23 \\
\hline $\mathrm{A} 2, \mathrm{~A} 2 \mathrm{~m}, \mathrm{FE} 8$ & $\mathrm{~W} 12 \times 96$ & $\mathrm{~W} 14 \times 38$ & $\mathrm{~L} 6 \times 4 \times 1 / 2$ & & & & & \\
\hline Test 3 & $\mathrm{~W} 8 \times 24$ & $\mathrm{~W} 8 \times 21$ & $\mathrm{~L} 6 \times 3 \frac{1}{2} \times 3 / 8$ & 152.4 & 50.8 & 88.9 & 69.9 & \\
\hline FE1, FE7 & $\mathrm{W} 12 \times 96$ & $\mathrm{~W} 14 \times 38$ & $\mathrm{~L} 6 \times 4 \times 3 / 4$ & 203.2 & 63.5 & 139.7 & 88.9 & \\
\hline FE2 & $\mathrm{W} 12 \times 96$ & $\mathrm{~W} 14 \times 38$ & $\mathrm{~L} 6 \times 3 \frac{1}{2} \times 3 / 8$ & & 50.8 & & & \\
\hline FE3 & $\mathrm{W} 12 \times 96$ & $\mathrm{~W} 14 \times 38$ & $\mathrm{~L} 6 \times 6 \times 3 / 8$ & & 114.3 & & & \\
\hline FE4 & $\mathrm{W} 12 \times 96$ & $\mathrm{~W} 14 \times 38$ & $\mathrm{~L} 6 \times 4 \times 1 / 2$ & & 63.5 & & & 19.05 \\
\hline FE9 & $\mathrm{W} 12 \times 96$ & $\mathrm{~W} 8 \times 28$ & $\mathrm{~L} 6 \times 4 \times 3 / 8$ & & & & & 22.23 \\
\hline FE10 & $\mathrm{W} 12 \times 96$ & $\mathrm{~W} 8 \times 28$ & $\mathrm{~L} 6 \times 4 \times 1 / 2$ & & & & & \\
\hline FE11 & $\mathrm{W} 12 \times 96$ & $\mathrm{~W} 8 \times 28$ & L6 $\times 4 \times 3 / 4$ & & & & & \\
\hline FE12, FE12 ${ }_{\mathrm{Po}}$ & $\mathrm{W} 12 \times 96$ & $\mathrm{~W} 8 \times 28$ & $\mathrm{~L} 6 \times 31 / 2 \times 3 / 8$ & & 50.8 & & & \\
\hline FE13 & $\mathrm{W} 12 \times 96$ & $\mathrm{~W} 8 \times 28$ & $\mathrm{~L} 6 \times 6 \times 3 / 8$ & & 114.3 & & & \\
\hline
\end{tabular}


Fig. 1 Geometrical measurements of connection Test 3

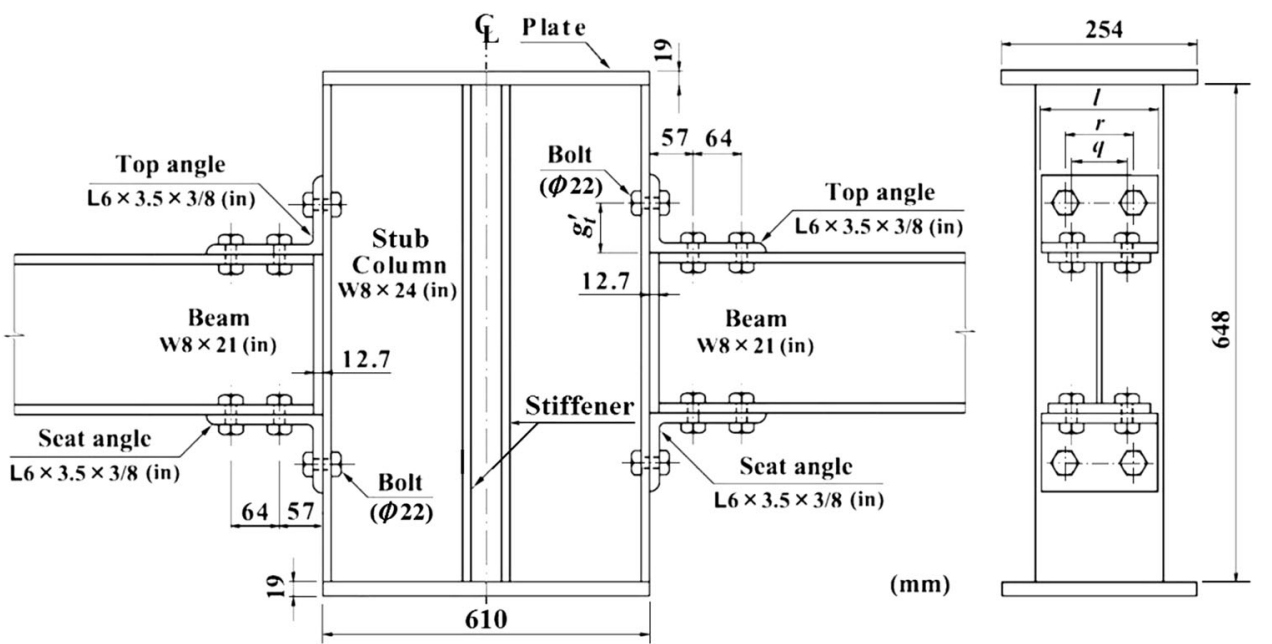

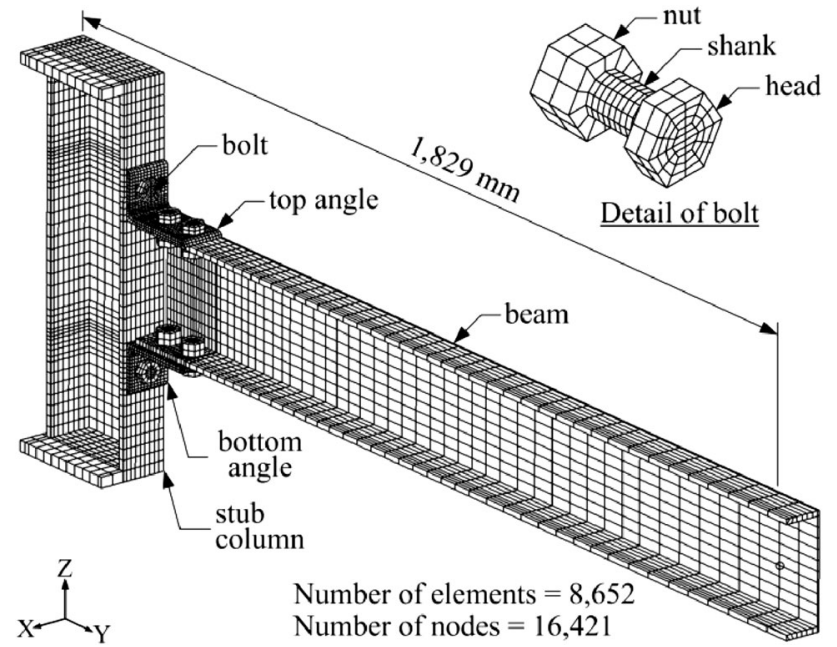

Fig. 2 Mesh pattern of FE model Test 3 with enlarged bolt

of the connection Test 3 with a bolt in enlarged configuration are shown in Fig. 2. The FE models similar to the experimental specimens A1, A2 and Test 3 are used for examination of the applicability of selected FE model of top- and seat-angle connection.

\section{Mechanical properties}

Material properties of angles and bolts for all connection models are listed in Table 2. Yield and ultimate stresses of angles, which are collected from experimental data, are 297 and $517 \mathrm{MPa}$ for Test 3, 301 and $467 \mathrm{MPa}$ for A1 and A2 connections, respectively. The properties of angles for the remaining connection models except models Test 3 and FE7 are kept same (Table 2) to investigate the effects of connection parameters, material properties and bolt pretension on prying action. Angle material properties for model FE7 is assumed to be the nominal values of A36 steel. Yield and ultimate stresses of beam and column of all connection models are assumed to be 365 and $550 \mathrm{MPa}$, respectively. Material properties for bolts of all connection models except FE8 are assumed to be of the nominal values of A325 bolts and for model FE8 are assumed to be of the nominal values of A490 bolts in accordance with AISCLRFD specification (2001). This was done because no coupon test results were included in the research reports of the tests. A bilinear stress-strain relation with isotropic hardening characteristics representing plastic behavior of all connection members is assumed. Young's modulus of elasticity, $E=206,000 \mathrm{MPa}$ and Poisson's ratio $v=0.3$ are taken. Here, strain hardening constant is determined assuming the ultimate strains are 10 and $20 \%$ for bolts and for the other connection members, respectively.

\section{Contact surface modeling}

To precisely analyze the behavior of connecting members, contact definition with finite sliding option is applied for the contact surfaces between the vertical legs of angles and column flange, between the horizontal legs of angles and corresponding beam flanges, and between the bolts and bolthole elements during the analysis. Moreover, to consider the frictional resistance between contact surfaces, the penalty frictional coefficient is assumed as 0.1 .

\section{Boundary condition}

FE models are analyzed consistent with the experimental setup of Azizinamini et al. (1985) and Harper (1990), in which (1) two beams are symmetrically connected to the column flanges in a cruciform shape (Fig. 1); (2) the ends of these beams are simply supported; and (3) letting the center of top plate of stub column move upward so that the forces corresponding to the prescribed bending moment 
Table 2 Mechanical properties of connection angles and bolts used for FE analysis

\begin{tabular}{|c|c|c|c|c|}
\hline \multirow[t]{2}{*}{ Test or FE model } & \multicolumn{2}{|l|}{ Angle } & \multicolumn{2}{|l|}{ Bolt } \\
\hline & $\begin{array}{l}\text { Yield stress } f_{y, t} \\
\text { (MPa) }\end{array}$ & $\begin{array}{l}\text { Ultimate strength } f_{u, t} \\
\text { (MPa) }\end{array}$ & $\begin{array}{l}\text { Yield stress } f_{y, b} \\
(\mathrm{MPa})\end{array}$ & $\begin{array}{l}\text { Ultimate strength } f_{u, b} \\
\text { (MPa) }\end{array}$ \\
\hline Test 3 & 297 & 517 & 635 & 830 \\
\hline $\mathrm{A} 1, \mathrm{~A} 2$ & 301 & 467 & & \\
\hline $\mathrm{A} 1 \mathrm{~m}, \mathrm{~A} 1_{\mathrm{Po}}, \mathrm{A} 2 \mathrm{~m}, \mathrm{FE} 1-\mathrm{FE} 6, \mathrm{FE} 9-\mathrm{FE} 13, \mathrm{FE} 12_{\mathrm{Po}}$ & 365 & 550 & & \\
\hline FE7 & 250 & 400 & & \\
\hline FE8 & 365 & 550 & 830 & 1035 \\
\hline
\end{tabular}

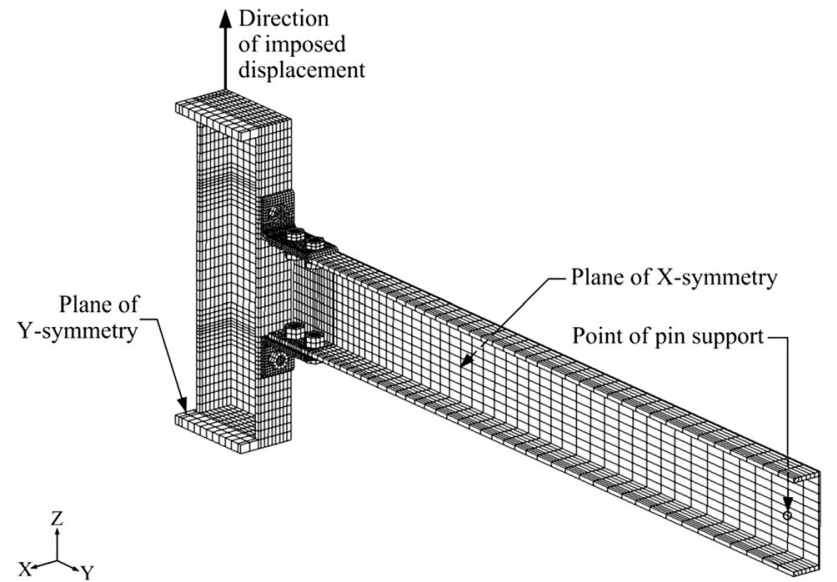

Fig. 3 Boundary conditions of the FE model of top- and seat-angle connections

can be distributed among the connection assemblages. In addition, rollers are used to correct any movement of the stub column due to slippage and asymmetric movement. Based on such experimental setup and considering structural symmetry, one-quarter model of connection composed of stub column, beam, top and seat angles and bolts is used for FE analysis modeling. Figure 3 demonstrates the boundary conditions applied to FE model. To enforce connection symmetry, plane $Z-X$ in the middle of the stub column is constrained in direction of $Y$ and plane $Y-Z$ in the middle of the beams and angles in length and stub column in width is constrained in direction $X$ (Fig. 3). To produce only vertical reaction forces, the beam end support is assumed to be pin.

\section{Loading method}

The analysis was carried out with a monotonically incremental loading scheme for all connection models imitating experimental loading procedure. The connection models are analyzed in three loading steps. In the first step, a prescribed force, $40 \%$ of minimum tensile strength of bolt, is applied to the pretension node of a predefined section of the bolt shank. As a result, the length of bolt shank at the pretension section changes by the amount necessary to carry the prescribed load. In the second step, the prescribed bolt load is replaced by changing the length of pretension section back to the initial length. Bolt pretension force of all models (excluding $\mathrm{A} 1_{\mathrm{Po}}$, FE5 and FE6) is prescribed as $40 \%$ of the ultimate strength of bolt. For connection models $\mathrm{A} 1_{\mathrm{Po}}, \mathrm{FE} 5$ and FE6, corresponding values are 0,20 and $60 \%$ of the ultimate strength of bolt, respectively. Thus, $\mathrm{A} 1_{\mathrm{Po}}$ connection model designated with subscript 'Po' as listed in Table 2 is analyzed considering zero pretension force of bolts. In the third step, bending moment is introduced to the beam-to-column connection by employing vertical displacement of the middle section of plane $Z-X$ of the stub column (Fig. 3). Automatic load increment scheme is preferred because ABAQUS can select the precise incremental rate to attain the optimum computational efficiency.

\section{Results of analysis and discussion}

Connection moment $M$ is determined by multiplying reaction force at the pin support of the beam and minimum distance between the point of pin support of beam and the instantaneous center of rotation. The instantaneous center of rotation for the connection is located at the cross-point of the horizontal middle plane and the vertical section at the top of the heel of angle leg adjacent to the compression beam flange (Fig. 4). Relative rotation of the connection $\theta_{r}$ calculated from the results of FE analysis is estimated using the following equation:

$\theta_{r}=\frac{\delta_{t}-\delta_{\mathrm{b}}}{h}$

where $\delta_{t}$ and $\delta_{\mathrm{b}}$ are the horizontal displacements at the upper and lower edges of beam flanges, respectively, and $h$ is the beam section height. In the FE analysis, connection moment is considered as the ultimate moment capacity 
when the first element of the top angle bolt or top angle of the FE model reaches at its ultimate stress level. The comparison of moment-rotation curves between analytical and experimental results is shown in Fig. 5 to verify the
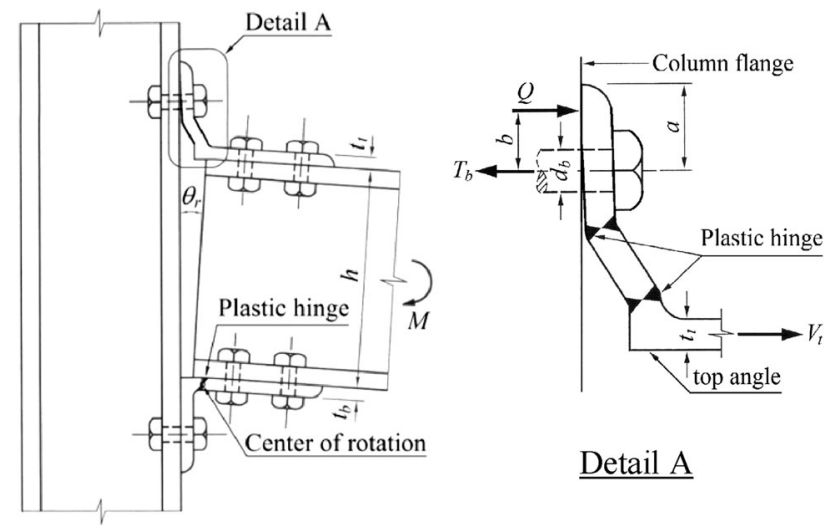

$\underline{\text { Detail A }}$ current FE analysis method. This comparison reveals that the computed moment-rotation curves are almost identical to the corresponding experimental ones in the linear elastic and early plastic ranges. The little differences in the late plastic range may have been caused by the following reasons (Ahmed 2002):

1. In the FE analysis, instead of actual nonlinear, an approximate linear inelastic constitutive behavior of angles and bolts material is used.

2. There might have some discrepancies between the material properties used for the FE analysis and those of test specimens.

3. Experimental error may also have contributed to the deviations.

Therefore, the FE analysis method is precise enough to investigate the magnitude of prying force and locations of the prying action and the yielding zones of the connection.

The stress-deformation results of the FE analyses show that yielding occurs initially at the top of the tension angle's filet (Fig. 6), and is then propagated in the area

Fig. 4 Deformed configuration of a typical top- and seat-angle connection
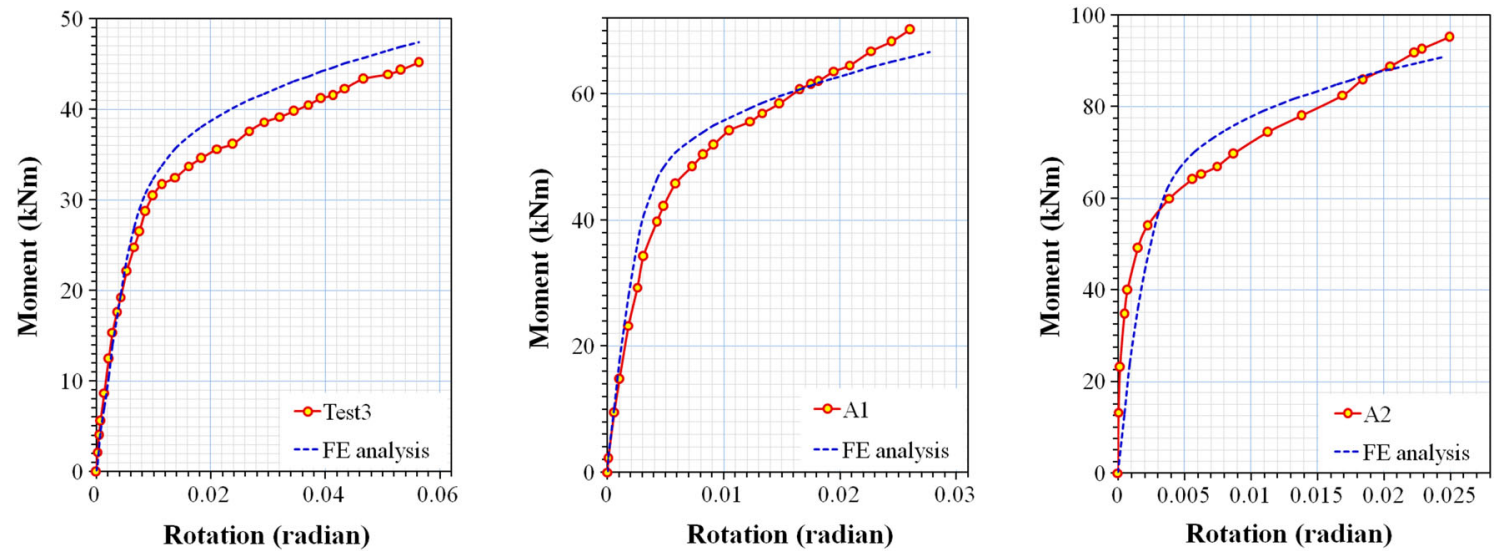

Fig. 5 Comparison of moment-rotation curves between FE analysis and experiment
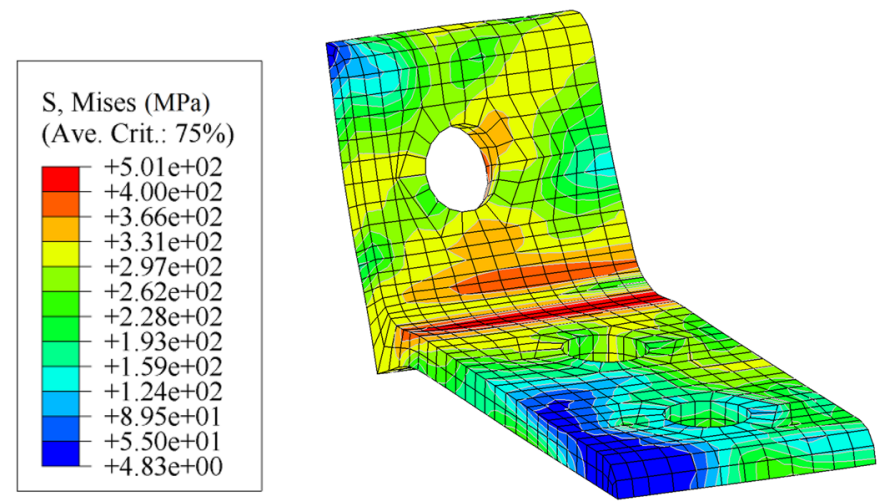

(a)

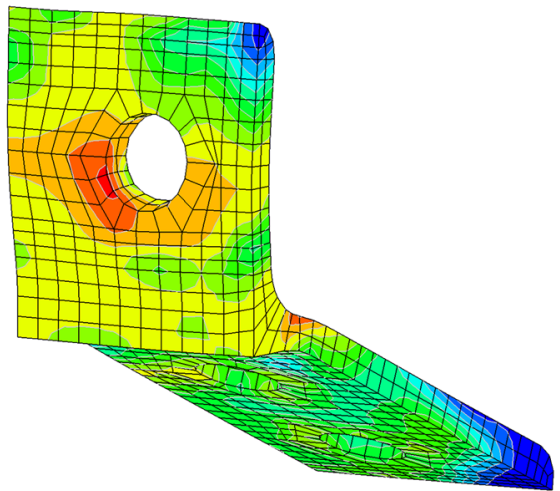

(b)

Fig. 6 Von Mises stress contour plot of top angle at the ultimate state $\left(M_{\mathrm{u}}=61.6 \mathrm{kNm}\right)$. a Front view. b Reverse view 

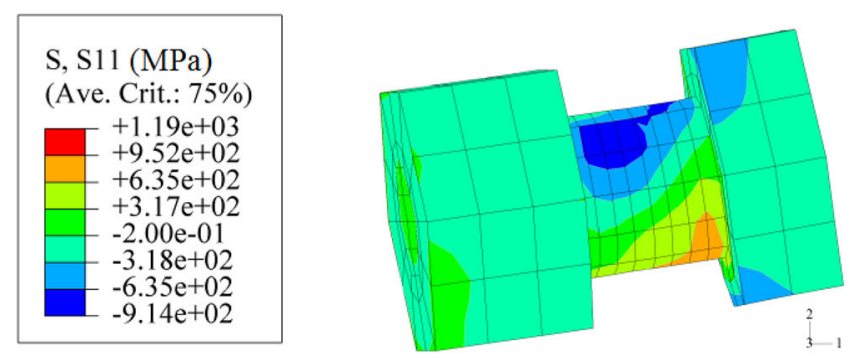

(a)

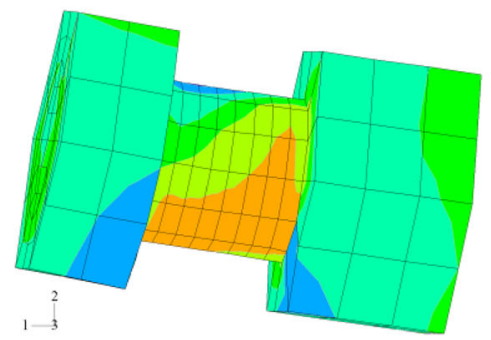

(b)

Fig. 7 Stress $\sigma_{11}$ contour plot of tension bolt at the ultimate state $\left(M_{\mathrm{u}}=61.6 \mathrm{kNm}\right)$. a Front view. b Reverse view

around the tension bolt head. Simultaneously, it is observed from FE analysis results that stresses higher than the yield point are generated in the bolt shank near the bolt head (Fig. 7), which indicates that the nonlinear behavior of the connection differs from some assumptions of the power model (Kishi and Chen 1990). With this observation, the place of formation of the upper plastic hinge in the top angle's vertical leg should be revised and an additional plastic hinge need to be added in the tension bolts to match with the results of FE analyses for the prediction model determining ultimate connection moment capacity.

$\mathrm{ABAQUS} /$ standard is able to estimate the pressure and its resultant force of a contact surface. In this study, the distributed pressure of the contact surface on the back of the top angle's vertical leg and its resultant which represents the relative prying force of the connection (illustrated in Fig. 4, Detail A) are investigated to determine the magnitude and location of prying force at the ultimate state of connections. Figure 8 illustrates nodal force distributions due to the contact pressure caused on the column-facing surface (back) of top angle's vertical leg. The illustrations in Fig. 8 demonstrate the numerical results for three loading stages: (a) the initial step before the connection moment is introduced (Fig. 8a); (b) near the elastic limit (Fig. 8b); (c) in the middle of the plastic range (Fig. 8c). In addition, contact surface pressure distribution on the back of the top angle's vertical leg and its location of the resultant at the ultimate state of connection are demonstrated in Fig. 9.

Figure 8a shows that contact pressure is almost uniformly developed on the back of the top angle's vertical leg under the bolt head area by the bolt tightening force and the contact nodal forces are moved to the upper area of the left-hand side of vertical leg as the connection moment increased up to the plastic range (Fig. 8b, c). The contact pressure distribution on the column surface facing top angle's vertical leg is accumulated at the upper area of the left-hand side of vertical leg. The resultant force due to the contact pressure is determined by summing up nodal forces developed on the contact surface that was defined as slave surface in contact definition between the two surfaces. This resultant is located in the contact area at a distance $b$ from the centerline of bolt hole at the ultimate state of the connection (Fig. 9). It should be noted that this contact pressure resultant at the ultimate state of a connection should be considered as the prying force.

\section{Distribution of forces in tension bolt (Ahmed 2002)}

Figure 10a shows the distribution of internal forces in tension bolt for model FE12 $2_{\text {Po }}$ in which initial bolt pretension is ignored. The total tensile force in bolt, which is shown by solid curvilinear line in Fig. 10a, is the summation of shear force (developed in top angle's vertical leg at the top of filet) illustrated with solid straight line in Fig. 10a and prying force. It can be observed from the figure and Table 3 that bolt tensile force $\left(V_{t}+Q\right)$ for model FE12 is 1.87 times higher than shear force $\left(V_{t}\right)$ at the ultimate state. So, it is obvious that the prying force $(Q)$, which is caused by the deformation of top angle's vertical leg, adds extra tensile force in bolt.

In Fig. 10b, solid straight, broken and solid curvilinear lines represent top angle's vertical leg shear (beam tension flange force), summation of shear force at top angle's vertical leg and contact force due to bolt pretension, and bolt tensile force, respectively. Thus, the vertical difference in between broken and solid curvilinear lines demonstrates the prying force corresponding to the shear force (Fig. 10b). It is apparent from Fig. 10 that prying force is also introduced in the tension bolt in application of pretension force in bolts of model FE12. However, it is difficult to estimate the prying force working on tension bolts because bolt tensile force consists of three components: shear force at top angle's vertical leg, contact force due to bolt pretension, and prying force. Shear force is determined as the transferred force from beam flange; whereas, the other two forces can be determined as contact force that is the summation of contact force due to bolt pretension and prying force. To get the individual forces from the contact force, it is assumed that the distribution of prying force corresponding to the shear force for the case considering bolt pretension is similar to that for the case ignoring 
Fig. 8 Contour plot of nodal contact force distribution on the back of top angle's vertical leg. a Before the connection moment being introduced $(M=0)$. b Near the elastic limit $(M=19.6 \mathrm{kNm})$. c Middle of the plastic range $(M=47.8 \mathrm{kNm})$
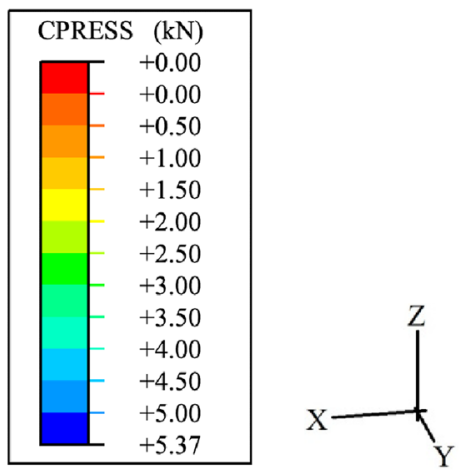

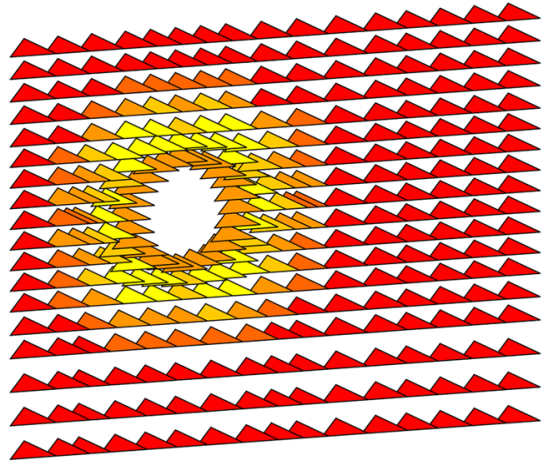

(a)

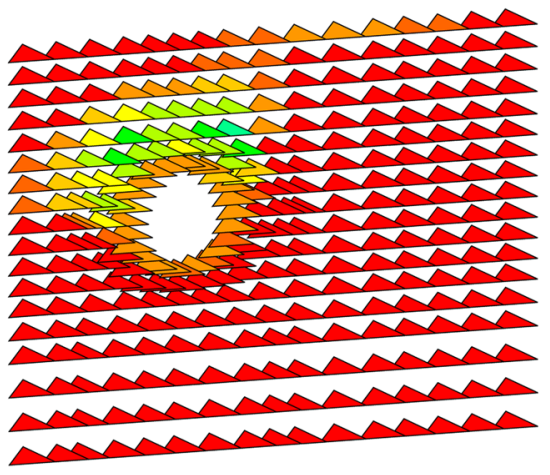

(b)

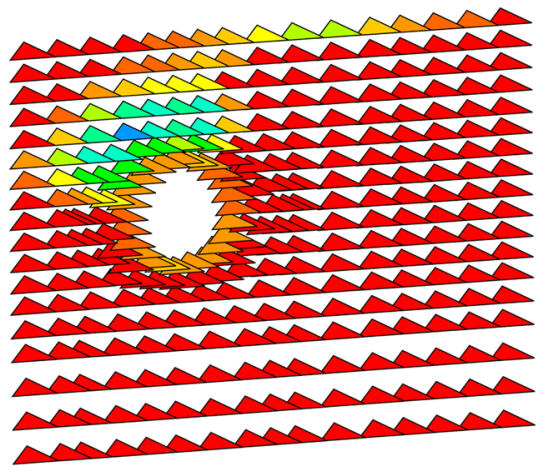

(c)
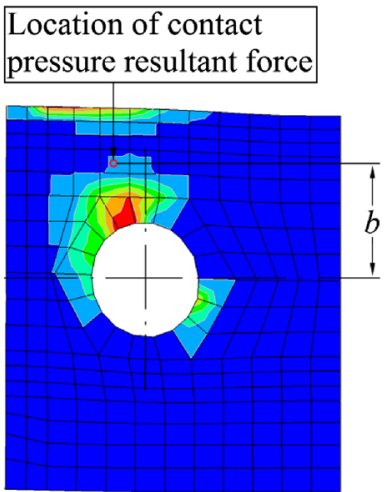

Fig. 9 Contour plot of contact surface pressure distribution on the back of top angle's vertical leg at the ultimate state $\left(M_{\mathrm{u}}=61.6 \mathrm{kNm}\right)$

pretension forces in bolts because distribution of prying is the same in both cases (considering and ignoring pretension forces in bolts) at the initial and ultimate level of loading (Figs. 10a, b, 11a). Even though, for the case considering pretension forces in bolts, the prying force may be little higher in the medium level of loading than in the case ignoring bolt pretension, it may not exceed $5 \%$ of the total tensile force of bolt and may be ignored to avoid complexity of calculation for determining prying force of the connection considering pretension forces in bolts. It is also confirmed later in Fig. 11a that distribution of prying force in both cases considering with/without pretension forces in bolts is almost the same according to the results obtained from the post-analysis investigation of the influence of bolt pretension on prying action. Figure 10b shows the distribution of forces in tension bolt of model FE12, which considers pretension forces in bolts. It is seen that three components of bolt force can be properly estimated. From this figure, it is observed that the component of contact force caused by pretensioning of bolts is decreased nonlinearly with increasing shear force of connection due to the bending effects of top angle's vertical leg.

\section{Influence of bolt pretension on prying force} (Ahmed 2002)

Initial pretension forces applied on models $\mathrm{A} 1_{\mathrm{Po}}$, FE5, $\mathrm{A} 1 \mathrm{~m}$, and FE6 are $0,20,40$, and $60 \%$ of the ultimate strength of bolt, respectively, and all the other properties are kept similar. In Fig. 11, the vertical difference in between two similar lines such as short dash and short dash with solid circle defines the magnitude of prying force corresponding to the shear force (tension flange force) for each bolt. It can be observed in Fig. 11a that bolt tensile 


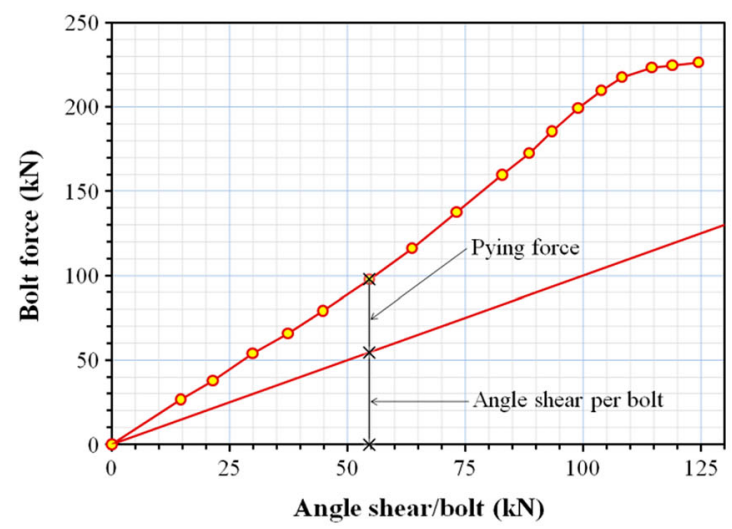

(a)

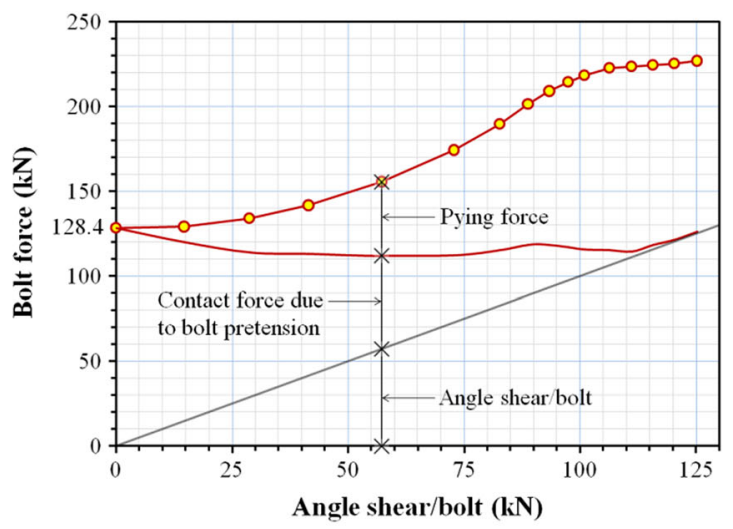

(b)

Fig. 10 Distribution of forces in tension bolt. a FEA model FE12 ${ }_{\mathrm{Po}}$. b FEA model FE12

Table 3 Summary of FE analysis results of connections and estimated $b$ distances

\begin{tabular}{|c|c|c|c|c|c|c|c|c|}
\hline \multirow[t]{2}{*}{ Connection ID } & \multicolumn{4}{|l|}{ FE analysis } & \multicolumn{2}{|l|}{ Proposed $b$} & \multicolumn{2}{|l|}{ Discrepancy } \\
\hline & $M_{\mathrm{u}}(\mathrm{kNm})$ & $V_{t}(\mathrm{kN})$ & $Q(\mathrm{kN})$ & $b(\mathrm{~mm})$ & Eq. (1) (mm) & Eq. (2) (mm) & Eq. (1) (\%) & Eq. (2) $(\%)$ \\
\hline Test 3 & 54.8 & 226.0 & 159.8 & 23.0 & 21.85 & 21.92 & -5.0 & -4.7 \\
\hline A1 & 75.2 & 190.0 & 238.7 & 19.4 & 21.85 & 21.29 & 12.6 & 9.7 \\
\hline $\mathrm{A} 2$ & 109.6 & 269.3 & 212.2 & 29.9 & 29.21 & 29.53 & -2.3 & -1.2 \\
\hline FE1 & 154.9 & 363.7 & 155.3 & 37.8 & 38.10 & 38.10 & 0.8 & 0.8 \\
\hline FE2 & 98.0 & 254.7 & 187.3 & 22.8 & 21.85 & 21.92 & -4.2 & -3.8 \\
\hline FE3 & 45.7 & 109.4 & 253.6 & 19.8 & 21.85 & 18.75 & 10.4 & -5.3 \\
\hline FE4 & 66.3 & 167.2 & 159.5 & 29.2 & 29.21 & 29.53 & 0.0 & 1.1 \\
\hline FE5 & 75.2 & 190.2 & 238.5 & 19.5 & 21.85 & 21.29 & 12.1 & 9.2 \\
\hline FE6 & 75.9 & 191.8 & 237.0 & 19.5 & 21.85 & 21.29 & 12.1 & 9.2 \\
\hline FE7 & 128.9 & 306.7 & 181.4 & 37.1 & 38.10 & 38.10 & 2.7 & 2.7 \\
\hline FE8 & 115.4 & 285.2 & 279.1 & 26.5 & 29.21 & 29.53 & 10.2 & 11.4 \\
\hline FE9 & 44.5 & 180.8 & 241.6 & 20.0 & 21.85 & 21.29 & 9.2 & 6.4 \\
\hline FE10 & 66.1 & 260.8 & 212.3 & 29.9 & 29.21 & 29.53 & -2.3 & -1.2 \\
\hline FE11 & 95.6 & 350.0 & 162.4 & 38.0 & 38.10 & 38.10 & 0.3 & 0.3 \\
\hline FE12 & 56.7 & 240.3 & 208.9 & 23.1 & 21.85 & 21.92 & -5.4 & -5.1 \\
\hline FE13 & 26.6 & 96.8 & 236.4 & 19.2 & 21.85 & 18.75 & 13.8 & -2.4 \\
\hline
\end{tabular}

forces of corresponding models starting from different levels of pretensioning get closer as external load increases, and ultimately meet in the same point. Thus, prying force near the ultimate level of loading is not affected by the magnitude of pretension force. At the higher level of loading, contact force due to pretensioning of bolts is entirely neutralized, and only prying force is retained.

\section{Influence of connection parameters on prying force (Ahmed 2002)}

\section{Bolt diameter}

To investigate the effect of bending stiffness of bolt on prying force, comparison has been made between FE4 and
A1m connection models in which bolt diameters $\left(d_{\mathrm{b}}\right)$ are taken to be $19.05 \mathrm{~mm}$ (3/4 in.) and $22.23 \mathrm{~mm}$ (7/8 in.), respectively, and pretension force is taken to be $40 \%$ of the ultimate strength of bolt keeping the other parameters and material properties the same. It is observed from Fig. 11b that prying force develops very similarly in both connection models at the beginning of loading, but near the ultimate state, connection model with larger bolt diameter develops higher prying forces.

\section{Angle thickness}

Angle thicknesses $\left(t_{t}\right)$ of connection models FE9, FE10 and FE11 are assigned to be $9.5 \mathrm{~mm}$ (3/8 in.), $12.7 \mathrm{~mm}$ (1/2 in.), and $19.1 \mathrm{~mm}$ (3/4 in.), respectively, and their other 


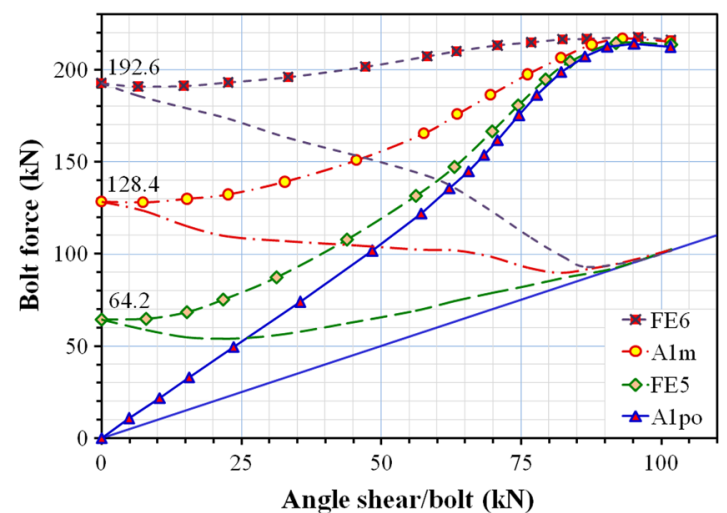

(a)

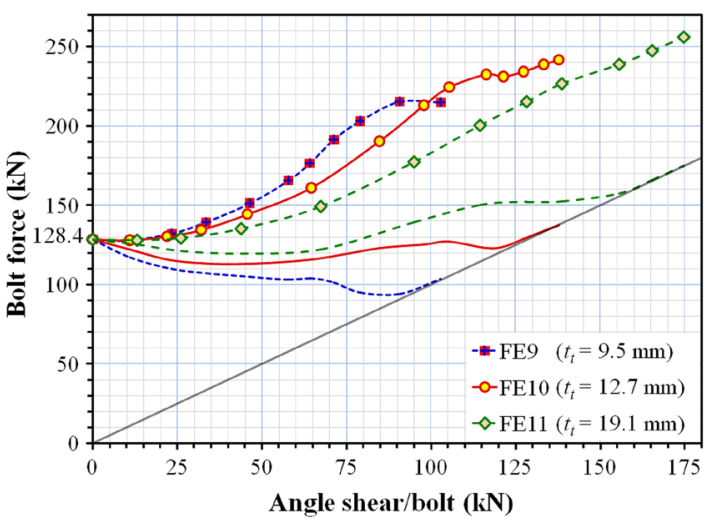

(c)

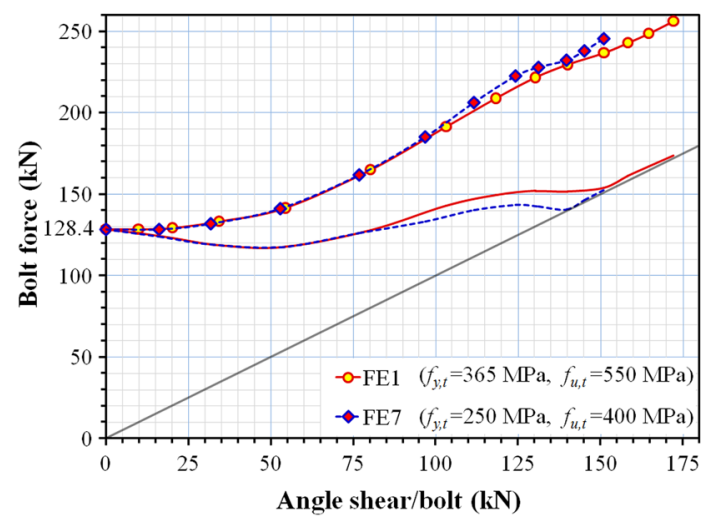

(e)

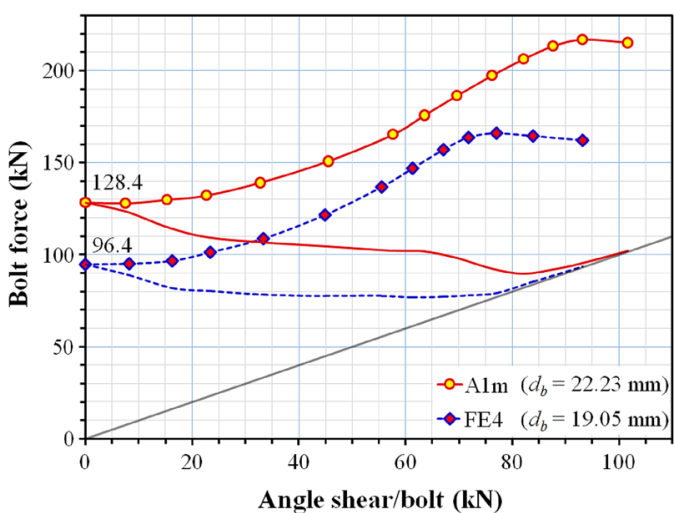

(b)

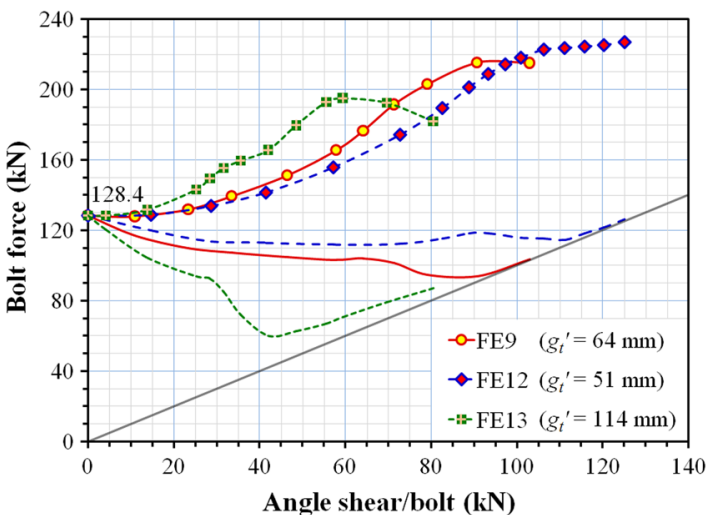

(d)

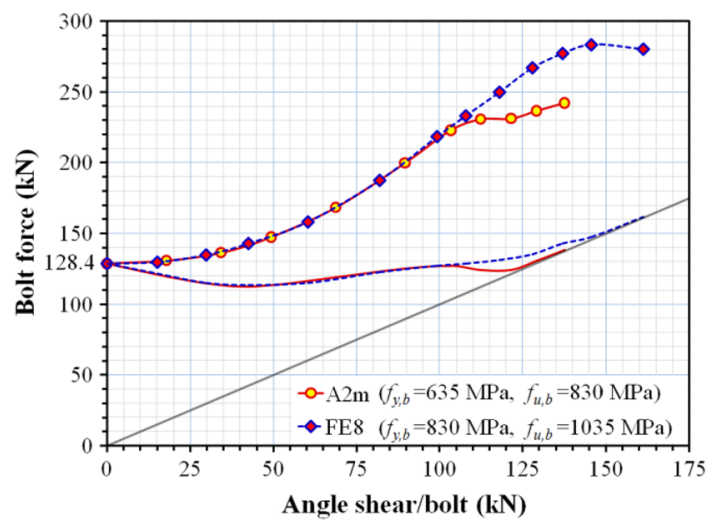

(f)

Fig. 11 Influence of bolt pretention, connection parameters and material properties on prying force a Bolt pretension. b Bolt diameter. c Top angle thickness. d Gage distance from angle heel to the centerline of bolt hole. e Material property of angle. $\mathbf{f}$ Material property of bolt

properties are kept the same. The effect of angle thickness on bolt force is depicted in Fig. 11c. Bolt tensile force in model FE9 increases most rapidly among the three models. The analysis results also show that prying force develops faster for thinner angle, and angle thickness is one of the most influential parameters to determine the contribution of prying action to the ultimate moment capacity of the connection.
Gage distance from the angle heel to the centerline of bolt hole

The gage distances from the heel to the centerline of bolt hole on top angle's vertical leg $g_{t}^{\prime}$ are taken to be $51 \mathrm{~mm}$ (2 in), $64 \mathrm{~mm}$ (2.5 in) and $114 \mathrm{~mm}$ (4.5 in) for connection models FE12, FE9, FE13, respectively, 
when the other properties of those connection models are the same. It is evident from Fig. 11d that prying force develops rapidly in connection with larger gage distance $g_{t}^{\prime}$ which also shows significant effect on prying action in determining connection's ultimate moment capacity.

\section{Influence of mechanical properties of connection assemblages on prying force (Ahmed 2002)}

\section{Angle's material}

All the measurements and material properties between FEA models FE1 and FE7 are the same except angle's material properties. The yield stress $f_{y, t}$ and ultimate strength $f_{u, t}$ of angles are 365 and $550 \mathrm{MPa}$, respectively, for model FE1 and 250 and $400 \mathrm{MPa}$, respectively, for model FE7. It is observed from Fig. 11e that connection model FE7 with thinner angles $\left(f_{y, t}=250 \mathrm{MPa}\right.$ and $f_{u, t}=400 \mathrm{MPa}$ ) develops a little greater prying force than that for connection model FE1 with thicker angles $\left(f_{y, t}=365 \mathrm{MPa}\right.$ and $\left.f_{u, t}=550 \mathrm{MPa}\right)$ at the final stages of loading.

\section{Bolt's material}

All the respective measurements and properties of models A $2 \mathrm{~m}$ and FE8 are the same except bolt mechanical properties. The yield stress $f_{y, b}$ and ultimate strength $f_{u, b}$ of bolts are assumed to be 635 and $830 \mathrm{MPa}$ for model A2 and 830 and $1035 \mathrm{MPa}$ for model FE8, respectively. It is observed in Fig. 10f that mechanical properties of bolt have no effect on prying action throughout the early and late middle loading ranges. But connection model FE8 with stiffer bolts $\left(f_{y, b}=830 \mathrm{MPa}\right.$ and $\left.f_{u, b}=1035 \mathrm{MPa}\right)$ exhibits a little increased prying force than the connection model $\mathrm{A} 2 \mathrm{~m}$ with weaker ones $\left(f_{y, b}=635 \mathrm{MPa}\right.$ and $\left.f_{u, b}=830 \mathrm{MPa}\right)$ at the ultimate state.

\section{Influence of connection parameters on distance $b$}

The location of the resultant of contact surface pressure is automatically generated by ABAQUS with respect to global axis. This resultant is known as prying force at the ultimate stage of loading. Later this location is determined from the centerline of bolt hole as shown in Table 3 by $b$. The table shows that the distance $b$ mostly depends on the thickness of top angle $t_{t}$ and gage distance $g_{t}^{\prime}$ from angle heel to the centerline of bolt hole. Other parameters, which influence this distance to some extent, are: bolt diameter, and material properties of angle and bolts (Table 3).

\section{Prediction of distance $b$ and assessment}

It is observed that the distance $b$ related to the location of prying force (i.e., resultant of contact pressure as shown in Fig. 9) action point from the centerline of bolt hole can be related to the angle thickness and can be expressed as

If $2.3 t_{t}<a$ then $b=2.3 t_{t}$ else $b=a$

The distance $b$ of the prying force action point from the centerline of bolt hole can also be linked to the angle thickness in combination with gage distance from angle heel to the centerline of bolt hole and can be determined as

$$
\begin{aligned}
& \text { If }\left(2.575 t_{t}-0.05 g_{t}^{\prime}\right)<a \text { then } \\
& \quad b=2.575 t_{t}-0.05 g_{t}^{\prime} \text { else } b=a
\end{aligned}
$$

where $a$ is the distance from the centerline of bolt hole to the top edge of tension angle's leg adjacent to column flange (Fig. 4), $t_{t}$ is thickness of top angle and $g_{t}^{\prime}$ is gage distance from angle heel to the centerline of bolt hole.

A brief summary of the FE analysis results and the proposed distance of the prying force location $b$ are listed in Table 3. This table shows that prying force $Q$ can be of as much as 2.4 times the shear force $V_{t}$ (i.e., beam flange force), and it must be considered in the calculation of the design resistance of the tension fasteners and of the ultimate connection moment. This table also shows that the performance of Eq. (3) over Eq. (2) estimating $b$ distance demonstrates superior in eleven cases, equal in three cases and inferior in only two cases. In addition, the maximum and minimum discrepancies in $b$ distance calculation by Eq. (3) are 11.4 and $-5.3 \%$, respectively. Corresponding discrepancies obtained using Eq. (2) are 13.8 and $-5.4 \%$, respectively. However, Eq. (2) is simpler as it uses only one parameter: tension angle thickness. But Eq. (3) shows superior results because of inclusion of more connection parameters to predict the distance of prying force from the center line of bolt hole of top angle's vertical leg. However, overestimation of the value of $b$ using Eq. (3) may be as high as $11.4 \%$. Overestimation of distance $b$ (in other words leads to conservative design) by the proposed equations could slightly decrease the predicted strength of the connections.

\section{Conclusions}

Confirming about the applicability of FE analysis model, the locations of plastic hinges at the ultimate state and the effects of prying force developing on the back of the top angle's vertical leg is investigated at the different loading levels of top- and seat-angle connection. Following conclusions are reached from this investigation: 
1. The plastic hinges develop at the top of the tension angle's filet and in the area around the tension bolt head of the vertical leg. Simultaneously, the other plastic hinge is developed in the bolt shank near the bolt head of the tension bolt, which indicates that the nonlinear behavior of the connection differs from some assumptions of Kishi and Chen's power model.

2. Prying force moves from the bolt head area to the upper area of the left-hand side of vertical leg as the connection moment increases from zero to the ultimate level.

3. Reduction of flange angle thickness or increment of gage distance from the angle heel to the centerline of bolt hole can increase the magnitude of prying force.

4. The location of prying force can be determined using the proposed expressions (Eqs. 2, 3). But Eq. (3) is recommended because of superior results.

5. Prying force can be of as much as 2.4 times the shear force at the vertical leg of top angle (i.e., beam flange force), and it must be considered in the calculation of the design resistance of the tension fasteners and the ultimate moment capacity of the connection.

Open Access This article is distributed under the terms of the Creative Commons Attribution 4.0 International License (http:// creativecommons.org/licenses/by/4.0/), which permits unrestricted use, distribution, and reproduction in any medium, provided you give appropriate credit to the original author(s) and the source, provide a link to the Creative Commons license, and indicate if changes were made.

\section{References}

ABAQUS (2005) Theory Manual, Version 6.10, Hibbitt Karlsson \& Sorensen, Inc., USA
ABAQUS/CAE (2005) User's Manuals, Version 6.10, Hibbitt Karlsson \& Sorensen, Inc., USA

Ahmed A (2002) Finite element analysis and modeling of $M-\theta_{r}$ relation for connections with angles, $\mathrm{PhD}$ Thesis, Department of Civil Engineering and Architecture, Muroran Institute of Technology, Muroran, Japan

Ahmed A, Kishi N, Matsuoka KG, Komuro M (2001) Nonlinear analysis on prying of top- and seat-angle connections. J Appl Mech JSCE 4:227-236

American Institute of Steel Construction (2001) Manual of Steel Construction, Load and Resistance Factored Design, AISC, vol I \& II, No. 2. Chicago

American Institute of Steel Construction (2005) Manual of Steel Construction, AISC Specification, Thirteenth edn. Chicago

Azizinamini A, Bradburn JH, Radziminski JB (1985) Static and cyclic behavior of semi-rigid steel beam-column connections, Structural research studies, Department of Civil Engineering, University of South Carolina, Columbia, S. C., March

CEN (1997) Eurocode 3, Part 1.1: Joint in Building Frames (Annex J), Comité Europeén de Normalisation, January

Faella C, Piluso V, Rizzano G (1996) Prediction of the flexural resistance of bolted connections with angles, IABSE Colloquium on Semirigid Structural Connections, Istanbul, pp 25-27, September

Harper WL (1990) Dynamic response of steel frames with semi- rigid connections, Structural research studies, Department of Civil Engineering, University of South Carolina, Columbia, S. C., May

Kishi N, Chen WF (1986) Data base of steel beam-to-column connections, Structural Engineering, Report No. CE-STR-86-26, School of Civil Engineering, Purdue University, West Lafayette, IN

Kishi N, Chen WF (1990) Moment- rotation relations of semi-rigid connections with angles. J Struct Eng ASCE 116(7):1813-1834

Komuro M, Kishi N, Ahmed A (2006) Elasto-plastic finite element analysis of prying of top- and seat-angle connections. Adv Eng Struct Mech Constr Solid Mech Appl 140:289-301 